\title{
Estudo eletroquímico do processo de eletrooxidação da prometazina empregando sensor a base de pasta de nanotubos de carbono contendo DNA imobilizado em matriz inorgânica
}

\section{Electrochemical study of oxidation process of promethazine using sensor based on carbon nanotubes paste containing immobilized DNA on inorganic matrix}

\author{
João Paulo Marco${ }^{1}$; Keyller Bastos Borges ${ }^{1}$; César Ricardo Teixeira Tarley²; Emerson \\ Schwingel Ribeiro ${ }^{3}$; Arnaldo César Pereira ${ }^{1}$
}

\begin{abstract}
Resumo
No presente trabalho foi estudado o comportamento voltamétrico e o processo de eletroeletrooxidação de prometazina (PHZ) em sensor eletroquímico baseado em pasta de nanotubos de carbono contendo DNA imobilizado em matriz inorgânica preparada pelo processo sol-gel $\left(\mathrm{SiO}_{2} / \mathrm{Al}_{2} \mathrm{O}_{3} / \mathrm{Nb}_{2} \mathrm{O}_{5}\right)$. Pelo método de Laviron verificou-se que o sistema é irreversível e com alta velocidade de transferência de elétrons entre o DNA e o eletrodo, indicando que o sensor proposto é cineticamente viável para promover a eletroeletrooxidação da PHZ. O estudo do efeito do $\mathrm{pH}$ sobre o processo de eletrooxidação da PHZ apresentou comportamento nernstiniano $(0,054 \mathrm{~V} / \mathrm{pH})$ sugerindo que o mesmo envolve a transferência de 2 prótons e 2 elétrons.
\end{abstract}

Palavras-chave: Prometazina. Comportamento eletroquímico. Processo de oxidação. NTCPM/DNA/ $\mathrm{SiO}_{2} / \mathrm{Al}_{2} \mathrm{O}_{3} / \mathrm{Nb}_{2} \mathrm{O}_{5}$.

\begin{abstract}
In the present work the voltammetric behavior and the oxidation process of promethazine (PHZ) in electrochemical sensor based on carbon nanotubes paste containing DNA immobilized on the inorganic matrix prepared by sol-gel process $\left(\mathrm{SiO}_{2} / \mathrm{Al}_{2} \mathrm{O}_{3} / \mathrm{Nb}_{2} \mathrm{O}_{5}\right)$. The method of Laviron verified that the system is irreversible and high speed of electron transfer between the electrode and DNA. The study of the oxidation of PHZ and influence of $\mathrm{pH}$ showed slope of $0.054 \mathrm{~V} / \mathrm{pH}$ (near the nernstian system: 0.0592 $\mathrm{V} / \mathrm{pH}$ ) suggesting that it involves the transfer of two protons and two electrons.

Keywords: Promethazine. Electrochemical behavior. Oxidation process. MWCNT/DNA/ $/ \mathrm{SiO}_{2} / \mathrm{Al}_{2} \mathrm{O}_{3} /$ $\mathrm{Nb}_{2} \mathrm{O}_{5}$.
\end{abstract}

\footnotetext{
${ }^{1}$ Aluno de Mestrado- Departamento de Ciências Naturais, Universidade Federal de São João del Rei (UFSJ), Campus Dom Bosco, Praça Dom Helvécio 74, Fábricas, 36301-160, São João del Rei, MG, Brasil.

${ }^{1}$ Professor Adjunto - Departamento de Ciências Naturais, Universidade Federal de São João del Rei (UFSJ), Campus Dom Bosco, Praça Dom Helvécio 74, Fábricas, 36301-160, São João del Rei, MG, Brasil. arnaldo@ufsj.edu.br

${ }^{2}$ Professor Adjunto - Departamento de Química, Universidade Estadual de Londrina (UEL), Centro de Ciências Exatas, Rodovia Celso Garcia Cid PR 445 Km 380, 86050-482, Londrina, PR, Brasil.

${ }^{3}$ Professor Adjunto - Departamento de Química Inorgânica, Instituto de Química, Universidade Federal do Rio de Janeiro (UFRJ), 21941-909, Rio de Janeiro, RJ, Brasil.
} 


\section{Introdução}

Os agentes antidepressivos tricíclicos convencionais (ATCs) foram descobertos a partir da síntese de derivados dibenzazepínicos, em 1951, inicialmente desenvolvidos e empregados terapeuticamente, por suas propriedades psicotrópicas, sedativas e analgésicas (ROMEIRO; FRAGA; BARREIRO, 2003). Quando usados em doses excessivas, os ATCs podem ser nocivos à saúde, levando até a morte do paciente. Mesmo em doses terapêuticas, há a ocorrência de diversos efeitos colaterais, tais como sonolência e sedação excessiva; confusão mental, secura da boca e visão turva. Sobre o aparelho cardiovascular há o aparecimento de taquicardia e modificações da pressão sanguínea quando administrados em superdosagem (TARLEY; SILVEIRA, 2008). Por isso, o controle do teor do medicamento administrado é importante para o sucesso do tratamento e minimização dos efeitos colaterais. A prometazina (PHZ) pertence à classe dos ATCs e pode ser administrada sob a forma de injetável, solução líquida oral, supositórios ou comprimidos revestidos (MARCO, et al., 2013a). Assim, sua determinação em formulações de matérias-primas e produtos farmacêuticos é extremamente importante.

O desenvolvimento de métodos analíticos mais sensíveis e seletivos, desde o preparo da amostra até a identificação e a quantificação das espécies de interesse, permite a obtenção de dados confiáveis para acompanhamento clínico no uso do fármaco (SHEN, et al., 2010). Fenotiazínicos e seus derivados formam um importante grupo de fármacos que são usados para o tratamento de distúrbios psíquicos, relacionados a transtornos de humor, como depressão e esquizofrenia. Por esta razão, a determinação de prometazina (PHZ) em formulações farmacêuticas e em fluidos biológicos é de suma importância (WEI, et al., 2008).

$\mathrm{Na}$ prática, inúmeros procedimentos experimentais têm sido relatados na literatura para a determinação deste composto, tais como: espectrofotometria quimiluminescência, eletroforese capilar e cromatografia gasosa. No entanto, essas técnicas experimentais são caras, pois exigem quase sempre longos tempos de tratamento envolvendo várias etapas de préconcentração ou extração, preparo de amostras, o que pode inserir erros relativos ao operador. Além disso, por causa dos efeitos nocivos de solventes orgânicos utilizados, a comunidade científica sugere a elaboração de métodos analíticos para reduzir a quantidade de reagentes e materiais utilizados em ensaios farmacêuticos, que são princípios da química verde (MADEJ; KOSCIELNIAK, 2008).

Desta forma, as técnicas eletroanalíticas tem provado ao longo dos anos, serem excelentes alternativas para a determinação de compostos farmacêuticos, uma vez que elas são simples, eficazes, requerem tempos de análise relativamente curtos sem a necessidade de derivatizações ou passos que consomem tempo de extração; e possuem notável sensibilidade de detecção, reprodutibilidade, facilidade de miniaturização e menor consumo de reagentes. Entre as técnicas eletroanalíticas empregadas para determinação do antidepressivo PHZ cita-se a voltametria cíclica (JESUS, et al., 2011) e a potenciometria (ALIZADE; AKHOUDIAN, 2010). É oportuno mencionar que nestas técnicas fez-se necessário efetuar a modificação química dos eletrodos base com intuito de elevar a detectabilidade e a seletividade do método eletroanalítico.

O uso de DNA como elemento modificador de eletrodos tem sido reportado na literatura principalmente devido a diferença do comportamento eletroquímico do analito de interesse na presença do DNA (WEI, et al., 2014). Adicionalmente, também pode atuar com materiais pré-concentradores de PHZ por meio do uso de eletrodos de grafite modificados com DNA (WANG, et al., 1996). De acordo com este trabalho, e considerando as propriedades marcantes dos nanotubos de carbono (NTC), no tocante a boa condutividade eléctrica, alta estabilidade química e resistência 
mecânica extremamente elevada, constata-se que o emprego de NTC em detrimento ao grafite é ainda mais atraente em propostas analíticas visando à modificação de eletrodos modificados com DNA (STAII, et al., 2005).

Uma melhoria considerável no preparo de sensores à base de materiais carbonáceos com DNA pode ser obtida fazendo uso de matrizes inorgânicas no preparo do compósito. Os eletrodos modificados com materiais inorgânicos incluindo óxidos mistos, zeólitas, fosfatos, $\gamma$-alumina e outros tipos atualmente formam uma nova classe de eletrodos quimicamente modificados e são utilizados geralmente com o objetivo de aumentar a estabilidade das espécies eletroativas imobilizadas. Esta melhoria ocorre devido ao caráter ácido destes materiais inorgânicos que podem apresentar interações ácido-base de Brønsted com o DNA (MARCO, et al., 2013b).

A síntese e a caracterização da matriz inorgânica $\mathrm{SiO}_{2} / \mathrm{Al}_{2} \mathrm{O}_{3} / \mathrm{Nb}_{2} \mathrm{O}_{5}$ foi recentemente publicada e investigada como um novo material préconcentrador de íons Cd(II) em solução (COSTA, et al., 2011), mostrando a exelente característica ácida desse material, e que pode ser usado nesse trabalho. De acordo com o exposto, este estudo tem como objetivo caracterizar eletroquimicamente o sensor a base de pasta de nanotubos de carbono contendo DNA imobilizado em $\mathrm{SiO}_{2} / \mathrm{Al}_{2} \mathrm{O}_{3} / \mathrm{Nb}_{2} \mathrm{O}_{5}$ como matriz inorgânica e avaliar o processo de eletrooxidação de PHZ sobre este sensor.

\section{Materiais e Métodos}

\section{Reagentes e Soluções}

Nanotubos de Carbono de Paredes Múltiplas (NTCPM) foram adquiridos da CNT Corporation Ltd (Incheon, Coréia) com diâmetro de 10-40 nm e comprimento de 5-20 $\mu \mathrm{m}$. DNA de esperma de arenque (Nome Científico: Clupea harengus), cloridrato de prometazina (PHZ), hidróxido de sódio, ácido nítrico e óleo mineral foram adquiridos da Sigma-Aldrich ${ }^{\circledR}$ (St. Louis, MO, EUA). Cloreto de potássio foi obtido da Sial ${ }^{\circledR}$ (São Paulo, Brasil). Grafite em pó puro, fosfato de sódio monobásico anidro foram obtidos da Synth ${ }^{\circledR}$ (Diadema, Brasil). Fosfato de sódio bibásico foi adquirido da $\operatorname{Vetec}^{\circledR}$ (Rio de Janeiro, Brasil). O material inorgânico $\left(\mathrm{SiO}_{2} / \mathrm{Al}_{2} \mathrm{O}_{3} / \mathrm{Nb}_{2} \mathrm{O}_{5}\right)$, obtido pelo processo sol-gel, foi preparado conforme procedimento descrito anteriormente (COSTA, et al., 2011). Este material foi fornecido pelo Prof. Dr. Emerson S. Ribeiro da Universidade Federal do Rio de Janeiro e será denominado SiAlNb. Todos os demais reagentes utilizados foram de grau analítico e suas soluções preparadas em água destilada e deionizada utilizando sistema Millipore Milli-Q (resistividade $\left.>18 \mathrm{M} \Omega \mathrm{cm}^{-1}, 25^{\circ} \mathrm{C}\right)$.

\section{Instrumentação e célula eletroquímica}

As medidas eletroquímicas foram realizadas num potenciostato/galvanostato modelo PGSTAT12 da Ecochemie acoplado a um microcomputador contendo o software GPES 4.9, empregando uma célula com tampa de PVC contendo seis orifícios: três para os eletrodos, um para entrada, um para saída de gás $\left(\mathrm{N}_{2}\right.$ de alto grau de pureza) e um para adição de reagentes.

$\mathrm{O}$ eletrodo de prata/cloreto de prata $(\mathrm{Ag} / \mathrm{AgCl})$ contendo $3 \mathrm{~mol} \mathrm{~L}^{-1}$ de cloreto de potássio $(\mathrm{KCl})$ foi empregado como referência, e uma espiral de platina como o eletrodo auxiliar.

O eletrodo de trabalho utilizado foi construído no próprio laboratório. Este dispositivo é basicamente um tubo de vidro de $15 \mathrm{~cm}$ de comprimento contendo um fio de níquel/cromo e na base um disco de platina com uma cavidade inferior com $4 \mathrm{~mm}$ de diâmetro interno e $1 \mathrm{~mm}$ de profundidade para a inserção da pasta a base de material carbonáceo.

O pH final das soluções tampão foram determinados por um pHmetro Digimed DM-20 e ajustado com soluções $1 \mathrm{~mol} \mathrm{~L}^{-1}$ de ácido clorídrico ( $\mathrm{HCl})$ ou $1 \mathrm{~mol} \mathrm{~L}^{-1}$ de hidróxido de sódio $(\mathrm{NaOH})$. 
Antes de cada experimento, a solução de trabalho foi borbulhada com $\mathrm{N}_{2}$ e, durante a realização do mesmo, o fluxo de gás foi mantido apenas sobre a superfície da solução.

\section{Preparação dos eletrodos de trabalho}

Para a imobilização do componente biológico (DNA) na superfície da matriz de sílica $\left(\mathrm{SiO}_{2} /\right.$ $\left.\mathrm{Al}_{2} \mathrm{O}_{3} / \mathrm{Nb}_{2} \mathrm{O}_{5}-\mathrm{SiAlNb}\right), 320 \mathrm{mg}$ de sílica foram adicionados em $60 \mathrm{~mL}$ de uma solução de DNA em concentração igual a $0,8 \mathrm{mg} \mathrm{mL} \mathrm{mL}^{-1}$ preparada em solução tampão fosfato $0,1 \mathrm{~mol} \mathrm{~L}^{-1} \mathrm{pH} 7$, permanecendo sob agitação mecânica durante 15 min e após esta etapa, $12 \mathrm{~h}$ em repouso para adsorção do componente biológico na matriz. Logo após, realizou-se a filtração e posteriormente procedeu-se a secagem deste material (sílica com DNA imobilizado) em temperatura ambiente, a qual foi denominada de SiAlNb-DNA. Após o processo de secagem preparou-se a pasta de NTCPM contendo o material SiAlNb-DNA previamente preparada. Esta pasta foi constituída por uma massa total de $60 \mathrm{mg}$ numa mistura utilizando a proporção 1:1 (m/m) entre a SiAlNb-DNA e o NTCPM com óleo mineral $(40 \mu \mathrm{L})$. A mistura foi homogeneizada introduzida na cavidade inferior do tubo de vidro descrito anteriormente, obtendo o eletrodo de pasta de NTCPM e sílica modificada com DNA, a qual foi denominada de NTCPM-SiAlNb-DNA para estudos contendo o analito PHZ.

\section{Estudo do comportamento eletroquímico do sensor NTCPM-SiAINb-DNA na ausência e presença de $\mathrm{PHZ}$}

O comportamento eletroquímico do sensor NTCPM-SiAlNb-DNA foi avaliado por voltametria cíclica (VC) na ausência e presença de PHZ. Todos os voltamogramas foram obtidos em solução 0,1 mol L-1 de tampão fosfato $\mathrm{pH} 7,0$ a $10 \mathrm{mVs}^{-1}$.

\section{Estabilidade operacional do sensor}

Foram realizados estudos quanto à estabilidade operacional do sensor através de vários ciclos redox. Cem ciclos redox a partir do emprego da técnica de voltametria cíclica foram obtidos com um mesmo eletrodo a base de NTCPM-SiAlNb-DNA no monitoramento de $1 \mathrm{mmol} \mathrm{L}^{-1}$ de $\mathrm{PHZ}$, realizados a $10 \mathrm{mVs}^{-1}$ em solução $0,3 \mathrm{~mol} \mathrm{~L}^{-1}$ de tampão fosfato pH 7,0.

\section{Processo de eletrooxidação do componente biológico no sensor proposto}

Informações sobre o processo de oxi-redução do componente biológico (DNA) imobilizado sobre a matriz da SiAlNb, na presença do NTCPM como matriz condutora foram adquiridas através da avaliação de voltamogramas cíclicos obtidos em diferentes velocidades de varredura, $v$, utilizando-se $10,0 \mathrm{~mL}$ de solução $0,3 \mathrm{~mol} \mathrm{~L}^{-1}$ de tampão fosfato pH 7,0. Os parâmetros cinéticos foram determinados com relação ao coeficiente de transferência de elétrons, $\alpha$, a constante de velocidade de transferência de elétrons, $k$ e o número de elétrons envolvidos entre o componente biológico e a solução tampão.

\section{Estudo do processo de eletrooxidação da PHZ utilizando o sensor NTCPM-SiAINb- DNA}

Informações sobre a eletrooxidação da $\mathrm{PHZ}$ na superfície do sensor NTCPM-SiAlNb DNA constituído por uma mistura utilizando a proporção 1:1 (m/m) entre a SiAlNb-DNA (na concentração de $0,8 \mathrm{mg} \mathrm{mL}^{-1}$ de DNA) e o NTCPM foram adquiridas através da avaliação de VCs obtidos em diferentes $v$, utilizando um volume total de $10,0 \mathrm{~mL}$ na célula eletroquímica contendo $\mathrm{PHZ}$ na concentração de $100 \mu \mathrm{mol} \mathrm{L} \mathrm{L}^{-1}$ em solução $0,3 \mathrm{~mol} \mathrm{~L}^{-1}$ de tampão fosfato $\mathrm{pH}$ 7,0 como eletrólito de suporte. 


\section{Resultados e Discussões}

Estudo do comportamento eletroquímico do sensor NTCPM-SiAINb modificado com DNA e não modificado na presença e ausência de PHZ

Para avaliar a atividade eletrocatalítica do sensor NTCPM-SiAlNb-DNA, voltamogramas cíclicos foram obtidos com este dispositivo no intervalo de potencial de 0,3 a $1,3 \mathrm{~V} v s . \mathrm{Ag} / \mathrm{AgCl}$ na ausência de PHZ (Figura 1).

Figura 1 (a) - Voltamogramas cíclicos obtidos com os seguintes sensores (1) NTCPM-SiAlNb; (2) NTCPM-SiAlNb-DNA na ausência de PHZ e (b) (1) NTCPM-SiAlNb e (2) NTCPM-SiAlNb-DNA na presença de $100 \mu \mathrm{mol} \mathrm{L}^{-1}$ de PHZ. Experimentos foram realizados em solução tampão fosfato 0,1 $\mathrm{mol} \mathrm{L}^{-1} \mathrm{pH} 7 \mathrm{av}=10 \mathrm{mVs}^{-1}$
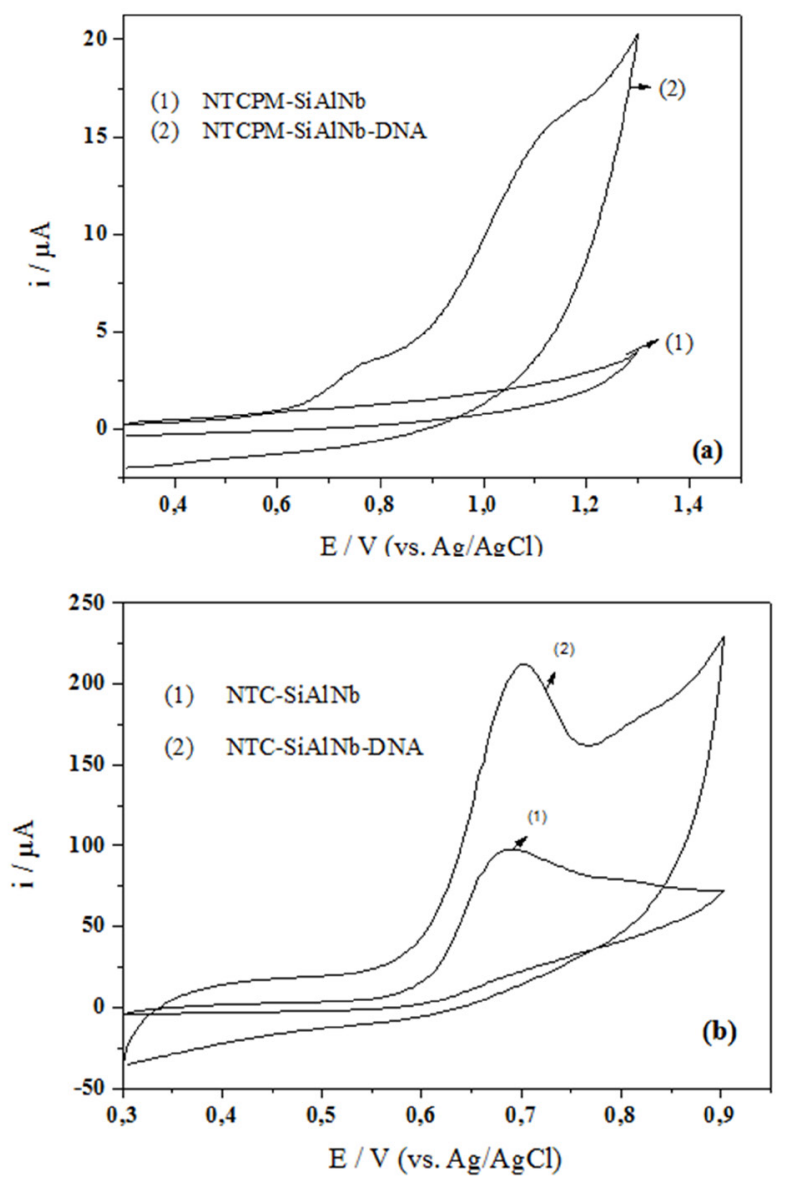

$\mathrm{Na}$ Figura 1a, dois picos anódicos foram detectados em potenciais de 0,8 e $1,1 \mathrm{~V}$ para $\mathrm{o}$ sensor NTCPM-SiAlNb-DNA. Esses picos podem ser atribuídos à eletrooxidação de resíduos das bases nitrogenadas guanina e adenina do DNA, respectivamente (ZHENG, et al., 2009). Quando comparado ao voltamograma cíclico obtido com eletrodo de trabalho preparado a base de NTCPMSiAlNb sem modificação, foi possível observar que nesse caso nenhum processo faradaico ocorreu no intervalo de potencial estudado, sendo este um resultado esperado.

Na Figura 1b, os voltamogramas cíclicos obtidos para os sensores NTCPM-SiAlNb e NTCPMSiAlNb-DNA na presença de $100 \mu \mathrm{mol} \mathrm{L}^{-1}$ de PHZ sugerem um efeito catalítico do DNA imobilizado sobre a superfície da SiAlNb e preparado num compósito a base de DNA para o processo de eletrooxidação do analito.

\section{stabilidade Operacional do Sensor TCPM-SiAINb-DNA}

A estabilidade operacional do sensor ssenvolvido para determinação de PHZ foi raliada por meio de 100 ciclos de varredura do tencial entre 0,3 a $0,9 \mathrm{~V}$ por $\mathrm{VC}$ utilizando o nsor NTCPM-SiAlNb-DNA. Assim, investigoua estabilidade da Ipa para o monitoramento de 1 mol L-1 de PHZ em solução tampão fosfato 0,3 ol L $\mathrm{L}^{-1} \mathrm{pH} 7$.

O valor da resposta analítica encontrada icialmente foi de $795 \mu \mathrm{A}$ (Tabela 1), e os demais )ltamogramas obtidos mostraram estabilidade do nal da corrente de pico anódica até 80 ciclos.

Fonte: Os autores 
Tabela 1 - Intensidade da corrente de pico anódica (Ipa) para o sensor NTCPM-SiAlNb-DNA após sucessivos voltamogramas cíclicos obtidos em solução tampão fosfato $0,3 \mathrm{~mol} \mathrm{~L}^{-1}, \mathrm{pH} 7$ a $10 \mathrm{mV}$ $\mathrm{s}^{-1}$ e $1 \mathrm{mmol} \mathrm{L}^{-1}$ de PHZ.

\begin{tabular}{cc}
\hline Ciclos & Ipa $(\boldsymbol{\mu A} \mathbf{A})$ \\
\hline 20 & 795 \\
40 & 788 \\
60 & 778 \\
80 & 756 \\
100 & 736 \\
\hline
\end{tabular}

Fonte: Os autores

Após 80 ciclos de varredura observou-se uma queda na intensidade de corrente de pico anódica menor que 5\%, indicando uma pequena lixiviação do componente biológico da superfície do eletrodo para a solução tampão. A diminuição da corrente também pode ser explicada com base no fenômeno do intumescimento da pasta de nanotubo de carbono durante a medida, dificultando a transferência de elétrons pela diminuição do contato íntimo entre os diferentes componentes da pasta. Embora ocorra uma pequena perda de sinal analítico, o sensor pode ser utilizado por várias horas, indicando forte interação do DNA com a matriz inorgânica e carbonácea. Lembrando, que essa perda na intensidade de corrente é menor do que outros eletrodos a base de pasta de nanotubo de carbono encontrado na literatura. Também, uma grande vantagem do uso da pasta de nanotubo de carbono é a sua renovação quando necessário.

\section{Determinação dos parâmetros cinéticos para o DNA imobilizado no compósito NTCPM- SiAINb-DNA}

Com intuito de estudar a cinética de transferência de elétrons do DNA sobre a superfície do eletrodo, foram estimados os parâmetros: $\alpha$ (coeficiente de transferência de elétrons), $k$ (constante de velocidade de transferência de elétrons) e $n_{e}$ (número de elétrons) para o DNA imobilizado na superfície da SiAlNb. A corrente de pico para espécies eletroativas é dada pela Equação (1) (CHEN et al., 2011):

$$
I_{p}=\frac{n e^{2} F^{2} v A \Gamma}{4 R T}
$$

Sendo que $I_{p}$ é a intensidade de corrente de pico, $F$ a constante de Faraday, $A$ a área do eletrodo, $v$ a velocidade de varredura, $\Gamma$ a quantidade de material biológico adsorvido sobre a superfície do material (SiAlNb) e incluída no compósito NTCPMSiAlNb-DNA $\left(\mathrm{mol} \mathrm{cm}^{-2}\right), R$ a constante dos gases, $T$ a temperatura e $n_{e}$ o número de elétrons participante na reação. $O$ valor de $n_{e}$ pode ser determinado através da equação descrita acima, se os outros parâmetros forem conhecidos. Embora a Equação (1) seja a forma mais utilizada para calcular o numero de elétrons participantes de reações redox, a teoria demonstra que a largura de meia altura do pico, $\delta_{0,5}$, medida em milivolts $(\mathrm{mV})$ deve ser igual a $90,6 / \mathrm{n}$ para o caso ideal (LAVIRON, 1982). Esta metodologia proposta por Laviron é mais simples e sua aplicação é restrita à espécies adsorvidas, como ocorre neste caso estudado. Desta forma, o sensor NTCPM-SiAlNb-DNA apresentou à baixas velocidades de varredura $\left(10 \mathrm{mV} \mathrm{s}^{-1}\right)$ para o primeiro pico (eletrooxidação da guanina) um $\delta_{0,5}$ em torno de $30 \mathrm{mV}$ e para o segundo pico (eletrooxidação da adenina) um $\delta_{0,5}$ em torno de $25 \mathrm{mV}$. Aplicando estes valores na relação mencionada anteriormente, para o sensor desenvolvido foram encontrados valores de $n_{e}$ como sendo 3,02 elétrons no caso do primeiro pico (guanina) e $n_{e}$ como sendo 3,62 elétrons para o segundo pico (adenina).

Estes resultados indicam que muito provavelmente para cada base nitrogenada oxidada (guanina e adenina), quatro elétrons participam do processo de eletrooxidação do DNA adsorvido sobre grafite, estando de acordo com a literatura (LA-SCALEA; SERRANO; GUTZ, 1999). Assim, estes resultados demonstram que a imobilização do DNA na matriz de sílica pode ter causado o bloqueio de alguns sítios catalíticos do DNA, refletindo num 
valor obtido de $\mathrm{n}$ (numero de elétrons) menor que o esperado. Embora este fenômeno possa ter ocorrido, o componente biológico (DNA) ainda apresenta capacidade de eletrooxidar o analito em estudo (PHZ) conforme verificado na Figura 1B.

Outro ponto a ser considerado para a obtenção do valor de $\mathrm{n}$ menor que o esperado é a alta resistência da matriz inorgânica, a qual é pouco condutora e pode dificultar a transferência de elétrons.

É importante mencionar neste ponto do trabalho que foi assumido que a espécie eletroativa (DNA) está adsorvida sobre o material inorgânico ( $\mathrm{SiAlNb}$ ), uma vez que o $\mathrm{Nb}_{2} \mathrm{O}_{5}$, age como um ácido de Lewis, promove uma excelente adsorção (interação ácido-base de Lewis) dos grupos básicos (bases nitrogenadas) presentes na estrutura do DNA (MARCO, et al., 2013b) sobre a superfície deste material. Desta forma, o método empregado para o cálculo do número de elétrons envolvido no processo redox do DNA imobilizado sobre a sílica sol-gel é idealmente aplicado quando a isoterma de Langmuir é obedecida, ou seja, a espécie eletroativa deve se encontrar adsorvida como uma monocamada, apresentando-se altamente dispersa na superfície da matriz inorgânica. Assim, foi empregada neste trabalho uma estimativa desta condição, uma vez que, o sistema obtido, constituído de nanotubo de carbono, DNA imobilizado sobre a matriz inorgânica e o óleo mineral possui uma estrutura bastante complexa.

Informações adicionais sobre o processo de eletrooxidação do DNA no compósito NTCPMSiAlNb foram obtidas por meio da avaliação da intensidade de corrente de pico anódica, $I_{p a}$, em função da velocidade de varredura. Assim, gráficos de $I p$ vs. $\mathrm{v}^{1 / 2}$ (Figura 2) foram obtidos para a eletrooxidação dos resíduos de guanina em $0,8 \mathrm{~V}$ e adenina em aproximadamente $1,1 \mathrm{~V}$ e em ambos os casos relações lineares foram obtidas.
Figura 2 - Dependência da corrente de pico em função da raiz quadrada da velocidade de varredura obtida para NTCPM-SiAlNb-DNA (a) $\mathrm{E}_{1}=0,8 \mathrm{~V}$ e (b) $\mathrm{E}_{2}=1,1 \mathrm{~V}$. Experimento realizado em solução tampão fosfato $0,3 \mathrm{~mol} \mathrm{~L}^{-1} \mathrm{pH} 7$.
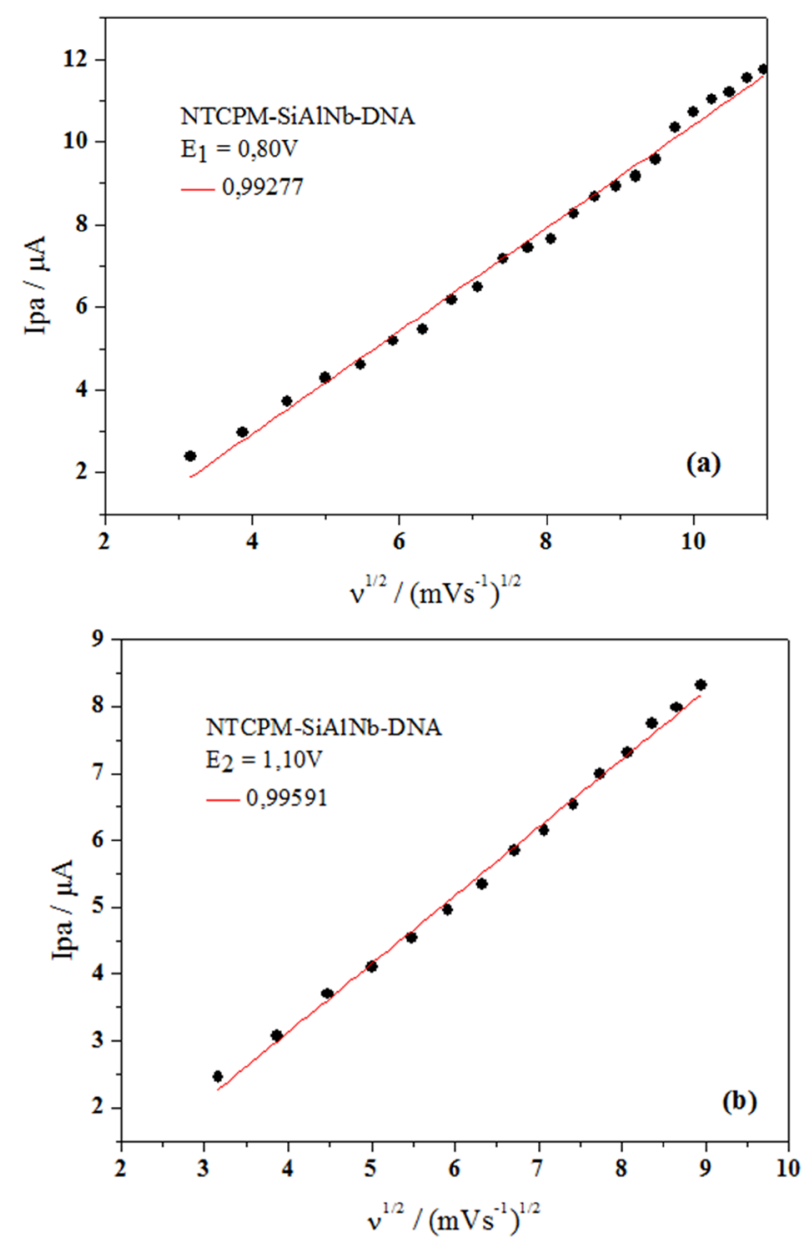

Fonte: Os autores

O processo redox do DNA na matriz de sílica apresentou um comportamento similar a um processo redox controlado por difusão, ou seja, o transporte de massa é o fator limitante do processo. Certamente, a característica porosa da matriz inorgânica preparada via processo sol-gel (COSTA, et al., 2011) influencia o processo de difusão e assim, os íons do eletrólito suporte (sistema tampão fosfato) não podem difundir facilmente para manter a eletroneutralidade da superfície do eletrodo. Além disso, nenhum decréscimo na corrente de pico após vários ciclos (Tabela 1) foi observado, indicando 
que o DNA, o qual possui várias bases nitrogenadas em sua estrutura, está fortemente adsorvido sobre a matriz SiAlNb (a qual atua como um ácido de Lewis). Assim, embora haja esta forte adsorção entre o DNA e a matriz inorganica, os estudos indicam que há uma correlação linear entre a corrente de pico e a raiz quadrada da velocidade de varredura (Figura 2) sugerindo um processo redox controlado por difusão.

Desta forma, o processo redox para o DNA adsorvido em matriz sol-gel, poderia ser controlado pela difusão dos contra-íons (as espécies que compõe o sistema tampão fosfato) para manter a eletroneutralidade sobre a superfície do eletrodo. Outras possibilidades para este comportamento são devido à resistência do material ou um mecanismo de transferência de elétrons ocorrendo por um mecanismo de elétron "hopping" (KUBOTA; GORTON 1999) ou ainda por um fluxo de prótons através dos poros.

De modo a observar o efeito de difusão nas propriedades cinéticas do DNA imobilizado sobre a matriz sol-gel, o coeficiente de transferência eletrônica, $\alpha$, e a constante de velocidade de transferência de elétrons, $k$, referente à transferência eletrônica entre o eletrodo e a espécie redox confinada à superfície foram estimadas por voltametria cíclica mediante avaliação do comportamento dos potenciais de pico anódico com o logaritmo da velocidade de varredura do potencial elétrico empregando o método de Laviron (1979).

A Figura 3 mostra as magnitudes dos potenciais de pico anódico em função do logaritmo da velocidade de varredura do potencial.
Figura 3 - Gráficos de Laviron $\left(\mathrm{E}_{\mathrm{pa}} v s . \log \mathrm{v} / \mathrm{Vs}^{1}\right)$ para a) primeiro pico anódico e ba) segundo pico anódico do DNA no sensor NTCPM-SiAlNb-DNA em solução tampão fosfato $0,3 \mathrm{~mol} \mathrm{~L}^{-1} \mathrm{pH} 7$.
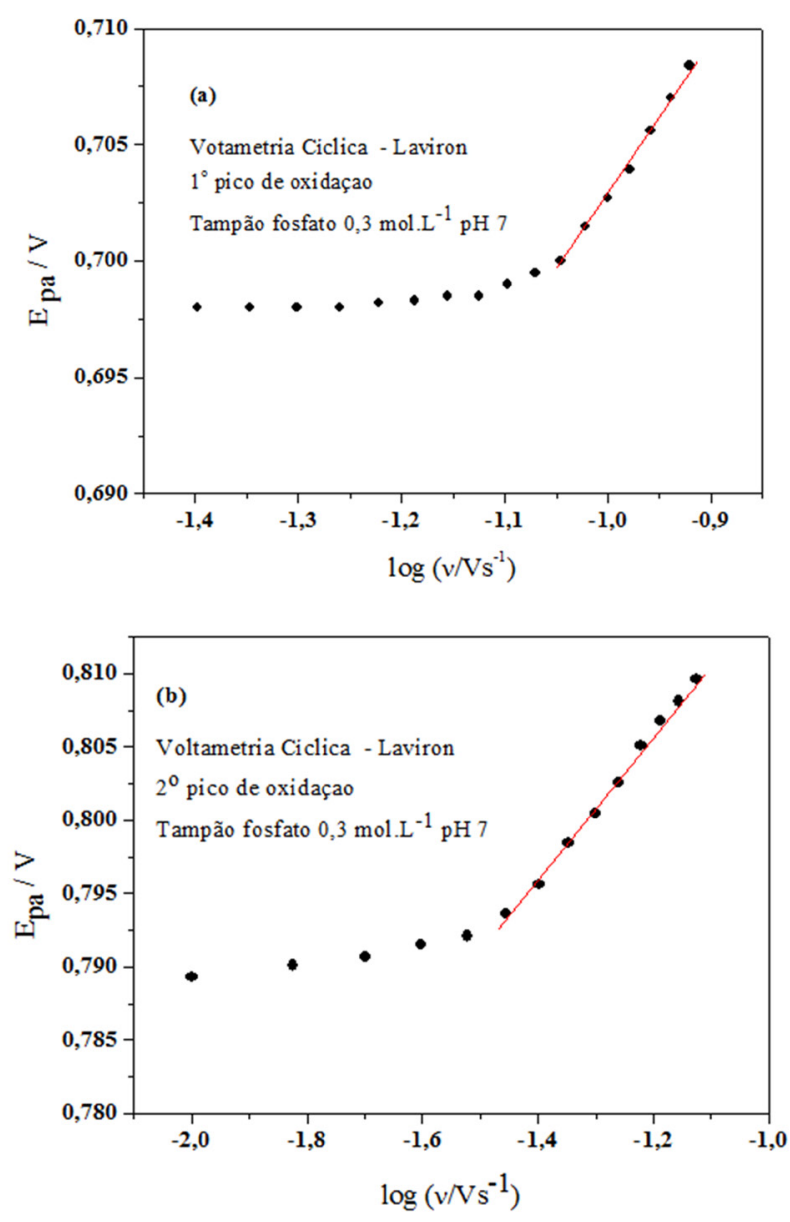

Fonte: Os autores

Em elevados valores de velocidade de varredura, verifica-se uma dependência linear entre $\mathrm{E}_{\mathrm{pa}}$ com $\log \left(\mathrm{v} / \mathrm{Vs}^{-1}\right)$, de forma que é possível extrair os parâmetros cinéticos $\alpha_{\text {anódico }}$ bem como $k$ a partir dos coeficientes lineares e angulares das curvas de Laviron.

O coeficiente angular para o segmento linear da curva de Laviron é dado pela expressão: 2,303RT $/ \alpha_{\mathrm{a}} \mathrm{e}$, para os picos anódicos. Os coeficientes angulares (para as curvas $\mathrm{Ep} / \mathrm{V}$ vs. $\log \mathrm{v} / \mathrm{Vs}^{1}$ ) encontrados para o primeiro pico de oxidação do DNA (referente ao processo redox da guanina) e para o segundo pico de oxidação do DNA (referente 
ao processo redox da adenina), foram iguais a 0,0669 e de 0,0499, respectivamente. A partir disso, os valores de $\alpha_{a}$ (anódico) obtidos empiricamente para os dois processos redox foram de 0,22 e 0,30 respectivamente, considerando quatro elétrons envolvidos no processo de eletrooxidação para cada pico. Estes resultados sugerem que a etapa de velocidade determinante para o processo de eletrooxidação do DNA é irreversível. Neste sentido, os valores de $\alpha_{a}$ iguais a 0,22 e 0,30 para os processos de eletrooxidação do componente biológico foram empregados para estimativa, empregando velocidade de varredura de $1 \mathrm{~V} \mathrm{~s}^{-1}$ (velocidade padrão sugerida por LAVIRON, 1979, 1982) da constante de velocidade de transferência de elétrons $(k)$, conforme a Equação 2 (LAVIRON, 1979):

$$
K=\frac{\alpha_{c} n e F v_{c}}{R T}=\frac{\alpha_{a} n e F v_{a}}{R T}
$$

Sendo $k$ representando a constante de velocidade de transferência eletrônica, $\alpha$ é o coeficiente de transferência de elétrons, $n_{e}$ é o número de elétrons envolvido, $v$ é a velocidade de varredura do potencial, $F$ é a constante de Faraday, $R$ e $T$ são as constantes dos gases e a temperatura, respectivamente. A partir da expressão anterior, os valores de $k$ estimados para o DNA foram de $34,3 \mathrm{~s}^{-1} \mathrm{e} 46,8 \mathrm{~s}^{-1}$, respectivamente.

Os valores estimados de $k$ para velocidades de varredura de $1 \mathrm{Vs}^{-1}$ em conjunto com os valores de $\alpha_{a}$, sugerem que o sistema é irreversível (que é verificado pela voltametria cíclica) e com alto valor da constante de velocidade de reação, sugerindo uma alta velocidade de transferência de elétrons entre o DNA e o eletrodo, permitindo uso destes materiais à base de DNA como potenciais sensores para espécies eletroativas como, por exemplo, a PHZ, uma vez que além das características cinéticas apropriadas, ainda apresentou alta estabilidade devido a uma boa adsorção obtida empregando-se a matriz sol-gel como suporte de imobilização do DNA.

\section{Estudo da eletroeletrooxidação de $\mathrm{PHZ}$ através do compósito NTCPM-SiAINb-DNA}

Visando estudar a cinética de transferência de elétrons entre o DNA no compósito NTCPM-SiAlNb e o analito PHZ, foram estimados os parâmetros: $\alpha, k$ e $n$ para a catálise com a espécie eletroativa de interesse. Informações sobre o processo de eletrooxidação foram obtidas através da análise da corrente de pico anódica, $I_{p a}$, por voltamogramas cíclicos deste dispositivo em solução contendo 1 mmol L ${ }^{-1}$ de PHZ em solução tampão fosfato 0,3 $\mathrm{mol} \mathrm{L}^{-1} \mathrm{pH} 7,0$.

De acordo com o modelo teórico de Andrieux e Sevéant (1978) a $I_{p}$ é dependente da velocidade de varredura, v, conforme a Equação 3:

$$
I_{p}=0,0496 F A C_{o} D_{o}^{\frac{1}{2}}\left(\frac{F v}{R T}\right)^{\frac{1}{2}}
$$

Sendo $C_{o}$ é a concentração do analito, $D_{o}$ é o coeficiente de difusão do analito na solução, $F$ a constante de Faraday, $R$ e $T$ são a constante dos gases e a temperatura, respectivamente.

Desta forma, foi possível estabelecer uma relação linear entre a $I_{p}$ e a raiz quadrada da $v$, indicando que o sistema em estudo se comporta como um processo catalítico irreversível controlado por difusão. Assim, um gráfico da $I_{p}$ vs. $v^{1 / 2}$ foi obtido (Figura 4) e verificou-se uma relação linear entre a $I_{p a}$ da PHZ com a raiz quadrada da velocidade de varredura. Assim, o processo redox do DNA com a PHZ pode ser atribuído a um sistema difusional, ou seja, o transporte de massa é o fator limitante do processo. 
Figura 4 - Dependência da corrente de pico em função da raiz quadrada da velocidade de varredura obtida para a catálise da PHZ utilizando NTCPMSiAlNb-DNA. Experimento realizado em solução tampão fosfato $0,3 \mathrm{~mol} \mathrm{~L}^{-1} \mathrm{pH} 7$.

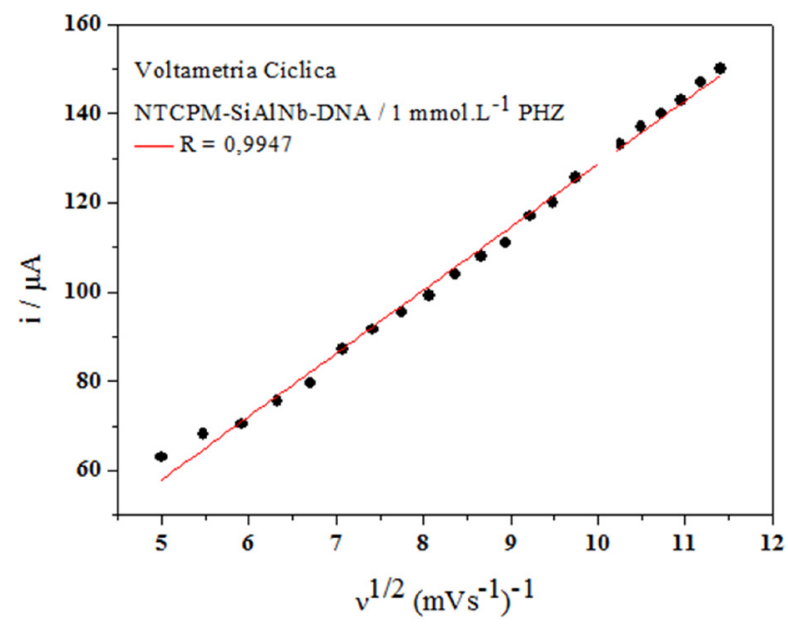

Fonte: Os autores

Como é esperado para um sistema irreversível, a $I p$ é dependente de $v^{1 / 2}$, e, portanto, o número de elétrons, $n$, envolvido na reação global de eletrooxidação da PHZ pode ser obtido a partir do coeficiente angular do gráfico Ip versus $v^{I / 2}$ de acordo com a equação 4 que caracteriza um sistema totalmente irreversível controlado por difusão (BARD; FAULKNER, 2001):

$$
\mathrm{I}_{\mathrm{p}}=\left(2,99 \times 10^{5}\right)\left[(1-\alpha) \mathrm{n}_{\mathrm{a}}\right]^{1 / 2} \mathrm{n} \mathrm{A} \mathrm{C}_{0}{ }^{4} \mathrm{D}_{0}^{1 / 2} v^{1 / 2}
$$

onde Ip é a corrente de pico, $n$ é o número total de elétrons envolvidos na reação, $\alpha$ é o coeficiente de transferência eletrônica, $n_{a}$, o número de elétrons envolvidos na etapa determinante da reação, $D_{0}$, o coeficiente de difusão da espécie eletroativa $\left(\mathrm{cm}^{2}\right.$ $\left.\mathrm{s}^{-1}\right), A$, a área do eletrodo, $C_{0}{ }^{*}$, a concentração da espécie eletroativa no seio da solução $\left(\mathrm{mol} \mathrm{cm}{ }^{-3}\right)$ e $v$, a velocidade de varredura. De acordo com a literatura (WEI, et al., 2008), o valor de $D_{0}$ para a PHZ é igual a $1,04 \times 10^{-3} \mathrm{~cm}^{2} \mathrm{~s}^{-1}$. Entretanto, antes de se obter o número total de elétrons envolvidos na reação de eletrooxidação de PHZ, foi necessário calcular o valor de $\left[(1-\alpha) n_{a}\right]$, a partir da seguinte equação 5:

$$
(1-\alpha) n_{a}=\frac{47,7 \mathrm{mV}}{E_{p}-E_{p / 2}}
$$

onde $E_{p}$ representa o potencial de pico e $E_{p / 2}$, o potencial de $I p$ a meia altura (BARD; FAULKNER, 2001).

Assim, o valor encontrado para $\left[(1-\alpha) n_{a}\right]$, utilizando-se para fins de cálculo o voltamograma obtido a $v=25 \mathrm{mV} \mathrm{s}^{-1}$ na presença de $1,00 \times 10^{-3} \mathrm{~mol}$ $\mathrm{L}^{-1}$ de $\mathrm{PHZ}$, similar àquele apresentado na Figura 1 (b), curva 2, foi igual a 0,56 . Substituindo esse valor, além de todos os outros valores pertinentes, na equação (5), foi possível obter um valor de $n$ igual a 1,8 , sugerindo que o mecanismo de eletrooxidação de PHZ sobre o NTCPM-SiAlNb-DNA envolve dois elétrons. Esse número de elétrons corrobora com dados determinados na literatura (JESUS et al., 2011).

A fim de comparação, a determinação dos parâmetros cinéticos referentes ao processo de eletroeletrooxidação da PHZ frente ao DNA imobilizado, foi realizada, empregou-se ainda o mesmo procedimento descrito anteriormente. Estes estudos foram realizados em solução tampão fosfato $0,3 \mathrm{~mol} \mathrm{~L}^{-1} \mathrm{pH}$ 7,0 e determinaram-se os valores de $k, \alpha$ e $n_{e}$ da catálise da $\mathrm{PHZ}$ promovida pelo sensor. O sensor NTCPM-SiAlNb-DNA apresentou, em baixas velocidades de varredura $\left(15 \mathrm{mVs}^{-1}\right)$, na presença de $1,0 \times 10^{-3} \mathrm{~mol} \mathrm{~L}^{-1}$ de PHZ, um $\delta_{0,5}$ em torno de $50 \mathrm{mV}$. Este resultado fortemente sugere que dois elétrons participam da reação redox, especialmente porque é conhecido que o mecanismo de eletrooxidação da PHZ em solução ocorrem em duas etapas com a formação de uma espécie intermediária que se oxida posteriormente envolvendo dois elétrons e dois prótons gerando dois picos principais relativamente fracos (JESUS et al., 2011). Aplicando esta relação para o sensor desenvolvido foram encontrados valores de $n_{e}$ como sendo 1,81 elétrons.

Desta forma, demonstrou-se que o numero de elétrons envolvidos no processo redox estudado 
(eletrooxidação do $\mathrm{PHZ}$ pelo DNA) é o mesmo por ambos os métodos aplicados, validando de certa forma a investigação do mecanismo reacional estudada.

A influência do $\mathrm{pH}$ sobre o potencial de pico anódico $\left(E_{p a}\right)$ de PHZ também foi verificada por voltametria cíclica, observando-se uma relação linear entre os referidos parâmetros na faixa de $\mathrm{pH}$ entre 5,0 e 7,5 (Figura 5).

Figura 5 - Influência do $\mathrm{pH}$ sobre o potencial de pico anódico $(E p a)$ determinado em solução $1 \mathrm{mmol}$ $\mathrm{L}^{-1}$ de PHZ. Medidas realizadas em solução $0,1 \mathrm{~mol}$ $\mathrm{L}^{-1}$ de tampão fosfato; $v=10 \mathrm{mV} \mathrm{s}^{-1}$.

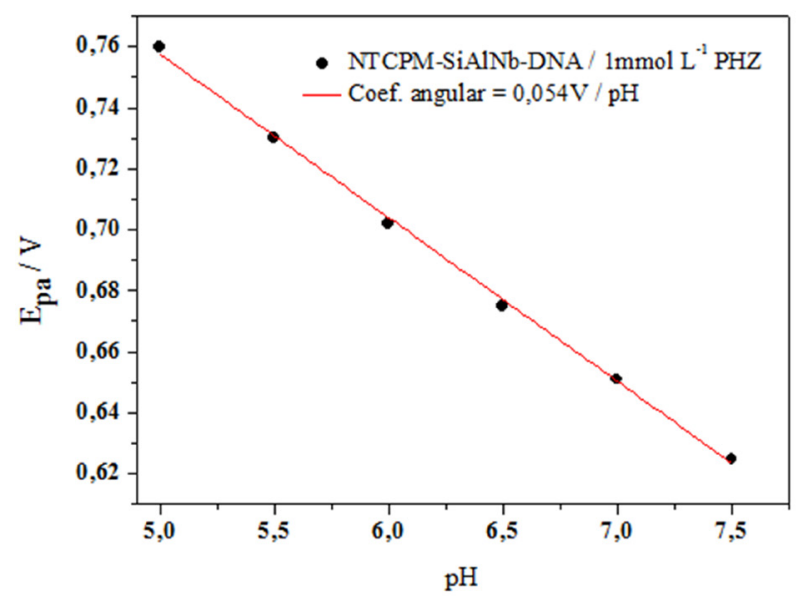

Fonte: Os autores

O coeficiente angular desse gráfico $(0,054 \mathrm{~V} /$ $\mathrm{pH})$ está muito próximo ao valor esperado para um sistema nernstiano $\left(0,0592\left(n_{p} / n_{e}\right) \mathrm{V} / \mathrm{pH}\right)$, onde o $n_{p}$ envolvidos na reação eletroquímica é igual ao $n_{e}$ (PAPOUCHADO, et al., 1975). Portanto, esse resultado sugere que no processo de eletrooxidação de PHZ sobre a superfície do sensor à base DNA proposto o $n_{p}$ é igual ao $n_{e}$ envolvidos. Desta forma, o Esquema I apresenta uma proposta de mecanismo para o processo de eletrooxidação da PHZ na superfície do sensor desenvolvido a base de DNA. O mecanismo proposto também tem sido reportado em recente publicação (CHEN et al., 2014).
Esquema I - Proposta mecanistica para o processo de oxidação eletroquímica de PHZ na superfície do NTCPM-SiAlNb-DNA (CHEN et al., 2014).
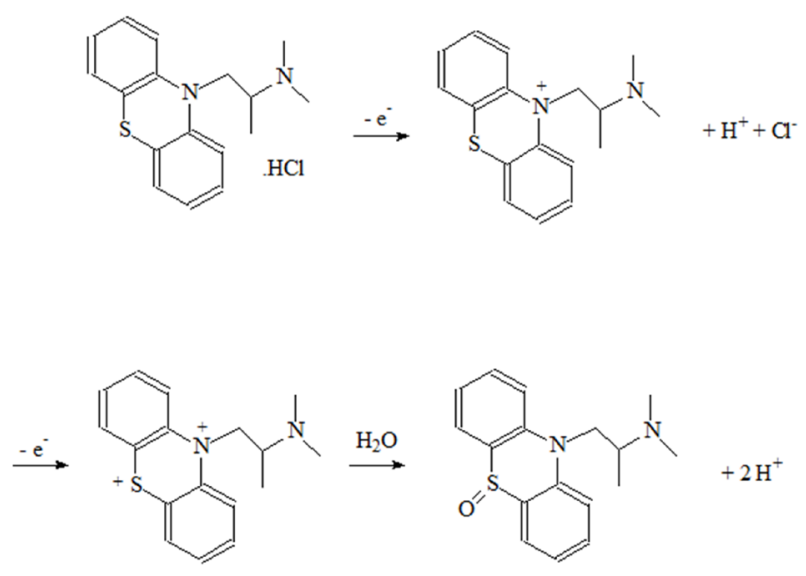

Neste processo oxidativo da PHZ promovido pelo sensor à base de NTCPM-SiAlNb-DNA, os voltamogramas obtidos apresentaram apenas um pico de eletrooxidação em potencial $0,65 \mathrm{~V} v s$. Ag/ $\mathrm{AgCl}$ contendo $3 \mathrm{~mol} \mathrm{~L}^{-1}$ de cloreto de potássio $(\mathrm{KCl})$. Uma possível explicação pode estar no fato que que o DNA imobilizado na matriz de sílica cataliza a eletrooxidação do analito numa única etapa envolvendo 2 elétrons, através da observação de um pico principal intenso

A Figura 6 apresenta o comportamento da interação entre o analito e o DNA imobilizado no NTCPM-SiAlNb-DNA o qual representa um modelo do tipo EC' (Eletroquímico - Químico Catalítico) para uma espécie em solução em seu estado reduzido que reage quimicamente com o produto da reação eletroquímica de forma que o catalisador é regenerado e o analito é oxidado (BOCKRIS, et. al., 2000). Neste sentido, um gráfico de função de corrente, $I_{p} / \mathrm{v}^{1 / 2}$, (corrente normalizada pela raiz da velocidade de varredura) foi construído a partir dos dados de corrente de pico e velocidade de varredura. 
Figura 6 - Relação entre a função de corrente (Ipa/ $\left.\mathrm{v}^{1 / 2}\right)$ versus a velocidade de varredura para 1,0 mmol $\mathrm{L}^{-1}$ de PHZ em solução $0,3 \mathrm{~mol} \mathrm{~L}{ }^{-1}$ tampão fosfato pH 7,0, utilizando NTCPM-SiAlNb-DNA.

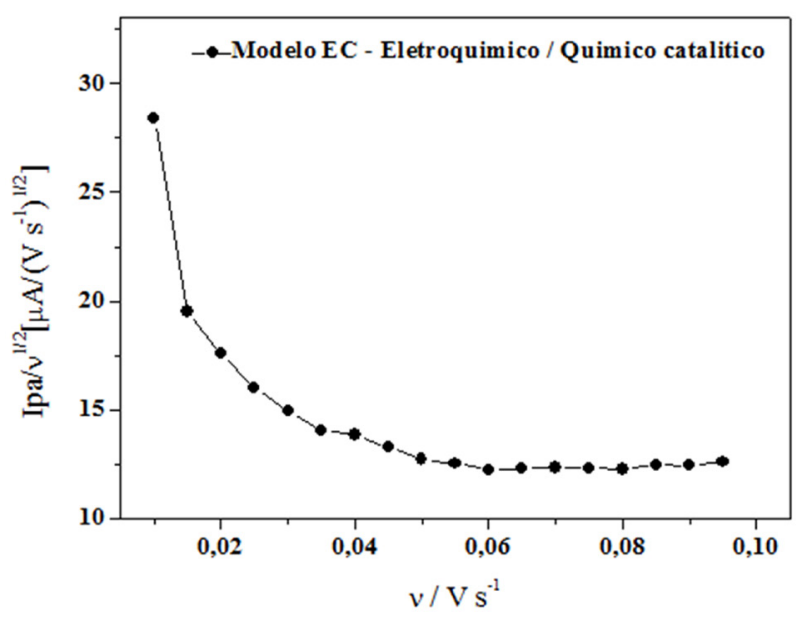

Fonte: Os autores

Conforme pode ser observado, o gráfico de função de corrente vs. velocidade de varredura resultou em um típico perfil observado para sistemas EC', no qual a função de corrente a baixas velocidades de varredura apresenta elevados valores e a altas velocidades de varredura a função de corrente converge para o coeficiente angular da curva $I_{p} v s . \mathrm{v}^{1 / 2}$ (Figura 4).

A Figura 7 mostra as magnitudes dos potenciais de pico anódico em função do logaritmo da velocidade de varredura do potencial.

Figura 7 - Gráfico de Laviron para o processo de eletrocatálise da PHZ promovida pelo DNA empregando o sensor NTCPM-SiAlNb-DNA. Experimento realizado na presença de 1,0x10-3 mol L-1 de PHZ em solução tampão fosfato $0,3 \mathrm{~mol} \mathrm{L-1}$ a $\mathrm{pH} 7,0$.

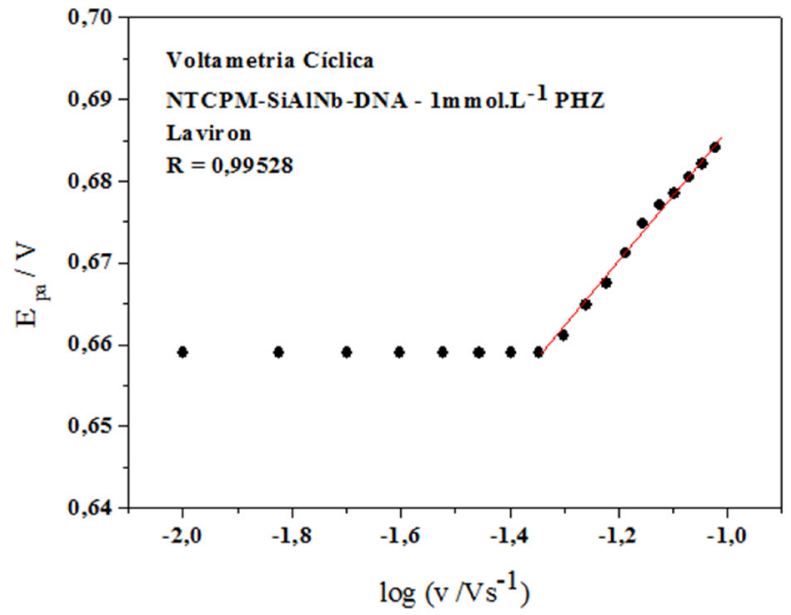

Fonte: Os autores

De acordo com a teoria, em elevados valores de velocidade de varredura, verifica-se uma dependência linear entre $E_{p a}$ com $\log \mathrm{v} / \mathrm{Vs}^{-1}$, de forma que é possível extrair os parâmetros cinéticos $\alpha$ anódico bem como $k$ a partir dos coeficientes lineares e angulares das curvas de Laviron.

Seguindo a mesma metodologia adotada na ausência do analito, neste caso, o coeficiente angular para o segmento linear da curva de Laviron é 2,303RT/ $\alpha_{a} n F$, para o pico anódico. Sendo que o coeficiente angular (para curva Ep/V vs. $\log \mathrm{v} / \mathrm{Vs}^{1}$ ) encontrado foi de 0,0684 . O valor de $\alpha$ anódico obtido empiricamente foi de 0,43 considerando dois elétrons envolvidos no processo de eletrooxidação. Neste sentido, o valor de $\alpha_{a}$ igual a 0,43 para o processo de eletrooxidação da PHZ foi empregado para a estimativa da constante de velocidade de transferência de elétrons $(k)$ conforme a Equação 2.

$\mathrm{O}$ valor de $k$ estimado para a catálise da $\mathrm{PHZ}$ foi de $33,5 \mathrm{~s}^{-1}$. Este valor estimado para velocidade de varredura de $1 \mathrm{Vs}^{-1}$ em conjunto com o valor de $\alpha$, sugerem que o processo é irreversível e com alto valor da constante de velocidade de reação para a catálise eletroquímica do analito, com resultados semelhantes ou melhores que outros trabalhos desenvolvidos utilizando sensores para determinação de PHZ (SALIMI; LASGHARI; 
NOORBAKHASH, 2010). Além disso, o sistema estudado apresentou cinética de transferência eletrônica apropriada para a avaliação do mecanismo de reação envolvendo DNA adsorvido e a espécie eletroativa, tal como a PHZ, o que é extremamente importante na área de compostos de interesse farmacológico.

Por fim, é importante mencionar que o comportamento eletroquímico do fármaco investigado (Prometazina), de um modo geral, em relação ao $\mathrm{pH}$, processo difusional, viabilidade cinética, avaliada a partir de valores de constante de velocidade de transferência de elétrons $(k)$, entre outros é similar a outros sensores apresentados na literatura (ALIZADEH; AKHOUNDIAN, 2010; ALIZADEH; GANJALI; AKHOUNDIAN, 2012; CHEN et al., 2014; LIMA; MONTENEGRO; SALES, 1997; PEREIRA, et al., 2014; RIBEIRO, et al., 2008; XI; MING; LIU, 2011) .

\section{Conclusões}

Este trabalho demonstra que a modificação da superfície do eletrodo foi efetuada de forma simples e efetiva, proporcionando grande estabilidade ao dispositivo desenvolvido. O sensor NTCPMSiAlNb-DNA foi capaz de promover um processo de eletrooxidação eletrocatalítico do analito, evidenciado pelo aumento significativo da $I_{p a}$. Verificou-se que é importante o emprego simultâneo dos NTCPM e da SiAlNb-DNA para que ocorra a eletrooxidação eletrocatalítica de PHZ. Tal eletrocatálise pode ser atribuída à baixa resistência de transferência de carga do compósito NTCPMSiAlNb-DNA, bem como a uma melhor dispersão e fixação do DNA na superfície da sílica, quando esse é utilizado junto com os NTC.

O processo de eletrooxidação do DNA imobilizado na sílica caracterizou-se por ser um processo irreversível controlado por difusão, no qual o transporte de massa é o fator limitante do processo, bem como mostrou envolver a participação de quatro elétrons na eletrooxidação de cada base nitrogenada e com elevada constante de transferência de elétrons para ser aplicado como componente catalítico na determinação de espécies de interesse.

O processo eletrocatalítico da $\mathrm{PHZ}$ caracterizouse por ser um processo irreversível controlado por difusão, bem como dependente do $\mathrm{pH}$, sendo, nesse caso, determinado com transferência de dois elétrons e com elevada constante de transferência de elétrons na catálise.

O valor de $k$ estimado para a catálise da $\mathrm{PHZ}$ para velocidade de varredura de $1 \mathrm{Vs}^{-1}$ em conjunto com o valor de $\alpha$, sugerem que o processo é irreversível e com alta velocidade de transferência de elétrons para a reação de catálise eletroquímica entre o DNA e o analito, com resultados semelhantes ou melhores que outros trabalhos desenvolvidos e reportados na literatura utilizando sensores para determinação de PHZ.

\section{Agradecimentos}

Os autores são gratos à Fundação de Amparo à Pesquisa do Estado de Minas Gerais (FAPEMIG), ao Conselho Nacional de Desenvolvimento Científico e Tecnológico (CNPq), à Coordenação de Aperfeiçoamento de Pessoal de Nível Superior (CAPES), ao INCT de Bioanalítica, à Fundação Araucária do Paraná, à Fundação Carlos Chagas Filho de Amparo à Pesquisa do Estado do Rio de Janeiro (FAPERJ) pelo apoio financeiro e bolsas de pesquisador, e ao estudante de iniciação científica Felipo Doval Rojas Soares do IQ/UFRJ pela preparação do material SiAlNb. Este trabalho é um projeto de colaboração entre os membros da Rede Mineira de Química (RQ-MG) financiado pela FAPEMIG. 


\section{Referências Bibliográficas}

ALIZADEH, T.; AKHOUNDIAN, M. A novel potentiometric sensor for promethazine based on a molecularly imprinted polymer (MIP): the role of MIP structure on the sensor performance. Electrochim Acta, v. 55, n. 10, p. 3477-3485, 2010.

ALIZADEH, T.; GANJALI, M. R.; AKHOUNDIAN, M. Fabrication of an extra sensitive voltammetric sensor using nanoparticles of molecularly imprinted polymer for determination of ultra-trace promethazine in plasma sample. International Journal of Electrochemical Science, v. 7, p. 10427-10441, 2012.

ANDRIEUX, C. P.; SAVEANT, J. M. Heterogeneous (Chemically modified electrodes, polymer electrodes) vs. Homogeneous catalysis of electrochemical reactions. Journal of Electroanalytical Chemistry and Interfacial Electrochemistry, v. 93, p. 163-168, 1978.

BARD, A. J.; FAULKNER, L. R. Electrochemical methods: Fundamentals and Applications. 2. ed. New York: John Willey \& Sons, 2001. 833 p.

BOCKRIS, J. O. M.; REDDY, A. K. N.; GAMBOAALDECO, M. E. Modern electrochemistry 2A: fundamentals of electrodics. United Kingdom: Springer Science \& Business Media, 2000.

CHEN, P. Y.; LUO, C. H.; CHEN, M. C.; TSAI, F. J.; CHANG, N. A.; SHIH, Y. Screen-printed carbon electrodes modified with cobalt phtalocyanine for selective sulfur detection in cosmetics products. International Journal of Molecular Sciences, v. 12, p. 3810-3820, 2011.

CHEN, T.; LIU, H.; LIU, Y.; YANG, Z. Sensitive electrochemical determination of promethazine hydrochloride based on the poly(p-aminobenzene sulfonic acid)/flowerlike $\mathrm{ZnO}$ crystals composite film. Analytical Methods, v. 6, p. 1203-1209, 2014.
COSTA, L. M.; RIBEIRO, E. S.; SEGATELLI, M. G.; NASCIMENTO, D. R.; OLIVEIRA, F. M.; TARLEY, C. R. T. Adsorption studies of $\mathrm{Cd}(\mathrm{II})$ onto $\mathrm{A} 12 \mathrm{O} 3 / \mathrm{Nb} 2 \mathrm{O} 5$ mixed oxide dispersed on silica matrix and its on-line preconcentration and determination by flame atomic absorption spectrometry. Spectrochimica Acta. Part B, v. 66, p. 329-337, 2011.

JESUS, C. G., FORTE, C. M. S., WOHNRATH, K., PESSÔA, C. A.; SOARES, J. E. S.; FUJIWARA, S. T.; NETO, P. L.; CORREIA, A. N. Electroanalytical Performance of $\left(\mathrm{SiPy}^{+} \mathrm{Cl}^{-} / \mathrm{CuTsPc}\right)_{5} \quad \mathrm{LbL}$ Film for Detecting Promethazine Hydrochloride. Electroanalysis, v. 23, p. 1814-1820, 2011.

KUBOTA, L. T.; GORTON, L. Electrochemical study of flavins, phenazines, phenoxazines and phenothiazines immobilized on zirconium phosphate, Electroanalysis, v. 11, p. 719-728, 1999.

LA-SCALEA, M. A.; SERRANO, S. H. P.; GUTZ, I. G. R. DNA-modified electrodes: A new alternative for electroanalysis. Quimca Nova, v. 22, p. 417-424, 1999.

LAVIRON, E. General expression of the linear potential sweep voltammogram in the case of diffusionless electrochemical systems. Journal of Electroanalytical Chemistry and Interfacial Electrochemistry, v. 101, p. 19-28, 1979.

LAVIRON, E. Voltammetric methods for the study of adsorbed species. Electroanal. Chem., v. 12, p. 53-157, 1982.

LIMA, J.; MONTENEGRO, M.; SALES, M. G. F. Ion-selective electrodes for promethazine determinations in pharmaceutical preparations and application to flow injection analysis. Journal of Pharmaceutical Sciences, v. 86, p. 1234-1238, 1997.

MADEJ, K.; KOSCIELNIAK, P. Review of analytical methods for identification and determination of PHEs and tricyclic antidepressants. Critical Reviews in Analytical Chemistry, v. 38, n. 2, p. 50-66, 2008. 
MARCO, J. P.; BORGES, K. B.; TARLEY, C. R. T.; RIBEIRO, E. S.; PEREIRA, A. C., Development of a simple, rapid and validated square wave voltametric method for determination of promethazine in raw material and pharmaceutical formulation using DNA modified multiwall carbon nanotube paste electrode. Sensors and Actuators B: chemical, v. 177, p. 251-259, 2013. (a).

MARCO, J. P.; BORGES, K. B.; TARLEY, C. R. T.; RIBEIRO, E.S.; PEREIRA, A. C. Development and application of an electrochemical biosensor based on carbon paste and silica modified with niobium oxide, alumina and DNA $\left(\mathrm{SiO}_{2} / \mathrm{Al}_{2} \mathrm{O}_{3} / \mathrm{Nb}_{2} \mathrm{O}_{5} /\right.$ DNA) for amitriptyline determination. Journal of Electroanalytical Chemistry, v.704, p. 159-168, 2013. (b).

PAPOUCHADO, L.; SANDFORD, R. W.; PETRIE, G.; ADMS, R. N. Anodic-oxidation pathways of phenolic compounds .2.stepwise electron transfers and coupled hydroxylations. Journal of Electroanalytical Chemistry and Interfacial Electrochemistry, v. 65, p. 275-284, 1975.

PEREIRA, P. F.; MARRA, M. C.; CUNHA, R. R.; SILVA, W. P.; MUNOZ, R. A. A.; RICHTER, E. M. Two simple and fast electrochemical methods for simultaneous determination of promethazine and codeine. Journal of Electroanalytical Chemistry, v. 713, p. 32-38, 2014.

RIBEIRO, F. W. P.; CARDOSO, A. S.; PORTELA, R. R.; LIMA, J. E. S.; MACHADO, S. A. S.; LIMA-NETO, P.; SOUZA, D.; CORREIA, A. N. Electroanalytical determination of promethazine hydrochloride in pharmaceutical formulations on highly boron-doped diamond electrodes using square-wave adsorptive voltammetry, Electroanalysis. v. 20, p. 2031-2039, 2008.

ROMEIRO, L. A. S.; FRAGA, C. A. M.; BARREIRO, E. J. Novas estratégias terapêuticas para o tratamento da depressão: uma visão da química medicinal. Química Nova, v. 26, n. 3, p. 347-358, 2003.
SALIMI, A.; LASGHARI, S.; NOORBAKHASH, A.; Carbon Nanotubes-ionic liquid and chloropromazine modified electrode for determination of NADH and fabrication of ethanol biosensor. Electroanalysis, v. 22, p. 1707-1716, 2010 .

SHEN, Y.; ZHU, R. H.; LI, H.; LIU, Y. W.; $\mathrm{XU}$, P. Validated LC-MS (ESI) assay for the simultaneous determination of amitriptyline and its metabolite nortriptyline in rat plasma: Application to a pharmacokinetic comparison. Journal of Pharmaceutical and Biomedical Analysis, v. 53, n. 3, p. 735-739, 2010.

SILVEIRA, G.; TARLEY, C. R. T. Determinação turbidimétrica do antidepressivo amitriptilina em sistema FIA explorando a formação do par iônico com lauril sulfato de sódio. Química Nova, v. 31, n.7, p. 1653-1659, 2008.

STAII, C.; JOHNSON-JUNIOR, A. T.; CHEN, N.; GELPERIN, A. DNA-decorated carbon nanotubes for chemical sensing. Nano Letters, v. 5, n. 9, p. 1774-1778, 2005.

WANG, J.; RIVAS, G.; CAI, X.; SHIRAISHI, H.; FARIAS, P. A. M.; DONTHA, N.; LUO, D. Accumulation and trace measurements of phenothiazine drugs at DNA-modified electrodes. Analytica Chimica Acta, v. 332, n. 21, p. 139-144, 1996.

WEI, L.; YUNSONG, Z.; XIA, Z.; XIAOLI, H.; XIAOHUA, Z. An implified impedimetric DNA sensor based on graphene oxide-phenylboronic acid for sensitive detection of bleomycins. New Journal of Chemistry, v. 28, p.2284-2291, 2014.

WEI, X.; ZHOU, Q. H. Q.; WU, J.; LU, L.; WANG, $\mathrm{X}$; YANG, X. Interaction between promethazine hydrochloride and DNA and its application in electrochemical detection of DNA hybridization. Electrochimica Acta, v. 53, n. 24, p. 7338-7343, 2008. 
XI, X.; MING, L. A.; LIU, J. Voltammetric determination of promethazine hydrochloride at a multi-wall carbon nanotube modified glassy carbon electrode. Drug Testing and Analysis, v. 3, p. 182186, 2011.

ZHENG, Y.; YANG, C.; PU, W.; ZHANG, J. Carbon nanotube-based DNA biosensor for monitoring phenolic pollutants. Microchim Acta, v. 166, p. 2126, 2009.

Recebido em 26 Maio, 2014 - Received on May 26, 2014

Aceito em 25 Agosto, 2014 - Accepted on August 25, 2014 